\title{
Development of coronary heart disease and ischemic stroke in relation to fasting and 2-hour plasma glucose levels in the normal range
}

Feng Ning ${ }^{1 *}$, Lei Zhang ${ }^{1,2,3,4}$, Jacqueline M Dekker ${ }^{5}$, Altan Onat ${ }^{6,7}$, Coen DA Stehouwer $^{8}$, John S Yudkin ${ }^{9}$,

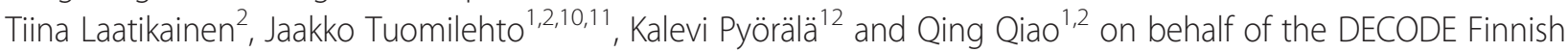
and Swedish Study Investigators

\begin{abstract}
Background: Individuals who had normoglycemia but whose 2-hour plasma glucose (2hPG) concentrations did not return to the fasting plasma glucose (FPG) levels during an oral glucose tolerance test (OGTT) have been shown to have increased cardiovascular mortality. This is further investigated regarding to the first events of coronary heart disease (CHD) and ischemic stroke (IS).

Method: Data from 9 Finnish and Swedish cohorts comprising 3743 men and 3916 women aged 25 to 90 years who had FPG $<6.1 \mathrm{mmol} / \mathrm{l}$ and $2 \mathrm{hPG}<7.8 \mathrm{mmol} / \mathrm{l}$ and free of CVD at enrolment were analyzed. Hazard ratios (HRs) for first CHD and IS events were estimated for the individuals with 2hPG > FPG (Group II) compared with those having $2 \mathrm{hPG} \leq \mathrm{FPG}$ (Group I).
\end{abstract}

Results: A total of 466 (115) CHD and 235 (106) IS events occurred in men (women) during a median follow-up of 16.4 years. Individuals in Group II were older and had greater body mass index, blood pressure, 2hPG and fasting insulin than those in Group I in both sexes. Multivariate adjusted HRs (95\% confidence intervals) for incidence of CHD, IS, and composite CVD events (CHD + IS) in men were $1.13(0.93-1.37), 1.40(1.06-1.85)$ and $1.20(1.01-1.42)$ in the Group II as compared with those in the Group I. The corresponding HRs in women were $1.33(0.83-2.13), 0.94$ (0.59-1.51) and 1.11 (0.79-1.54), respectively.

Conclusion: Within normoglycemic range individuals whose $2 \mathrm{hPG}$ did not return to their FPG levels during an OGTT had increased risk of CHD and IS.

Keywords: Normoglycemia, Coronary heart disease, Ischemic stroke, Incidence

\section{Background}

The role of hyperglycemia on the mortality from coronary heart disease (CHD) $[1,2]$, stroke $[3,4]$ and other cardiovascular diseases (CVDs) [5-7] has been well investigated. Two-hour plasma glucose (2hPG) is a better predictor than fasting plasma glucose (FPG) for incidence of CHD [8,9] and ischemic stroke (IS) [10] among individuals with hyperglycemia, but little is known about their impact within normoglycemic range. Previous studies have shown that insulin resistance and declined beta

\footnotetext{
* Correspondence: feng.ning@helsinki.fi

${ }^{1}$ Department of Public Health, Hjelt Institute, University of Helsinki, Helsinki, Finland

Full list of author information is available at the end of the article
}

cell function are already presented in subjects with elevated normal FPG and/or 2hPG [11-13]. The upper normal level of the FPG [14,15] or 2hPG [16] has been found to increase the risk of type 2 diabetes. Our previous finding based on the DECODE (Diabetes Epidemiology: Collaborative analysis Of Diagnostic criteria in Europe) study demonstrated that individuals with normoglycemia, whose $2 \mathrm{hPG}$ did not return to the FPG levels during a standard $75 \mathrm{~g}$ 2-h oral glucose tolerance test (OGTT) had a higher risk for mortality from CVD and all-cause than individuals whose 2hPG returned to their FPG levels or below them [17]. However, the early DECODE study could not show a causal relationship because individuals with CVD at baseline could not be 
identified and excluded. The elevated 2hPG could be a consequence of existing CVD rather than a cause. To further clarify the causal relationship between elevated normal 2hPG and the development of the CVD events, the current study is carried out based on the Finnish and the Swedish DECODE cohorts who have complete information on the occurrence of both fatal and nonfatal events.

\section{Participants and methods}

Data from 9 Finnish and Swedish cohorts comprising 3743 men and 3916 women aged 25 to 90 years who participated in the DECODE study were collaboratively analyzed. The maximum duration of follow-up ranged from 12.4 to 36.8 years among different cohorts with a median follow-up of 16.4 years. The study populations and methods used to recruit participants in the DECODE study had been described previously [18-21]. Briefly, the database was collected from researchers in Europe who had performed epidemiological surveys for diabetes using a standard 2-h OGTT. Individuals' data from participating study cohorts were sent to the Department of Chronic Disease Prevention of the National Institute for Health and Welfare in Helsinki, Finland for data analyses. In the current study, only the cohorts with the prospective data on fatal and non-fatal events with all required covariates of body mass index (BMI), blood pressure, total serum cholesterol and smoking status were included. Each study had been approved by the local ethics committees, and the ethics committee of the National Institute for Health and Welfare approved the collaborative data analysis.

BMI was calculated as weight in kilograms divided by height in meters squared $\left(\mathrm{kg} / \mathrm{m}^{2}\right)$. An individual with a prior history of hypertension or having a systolic blood pressure (SBP) $\geq 140 \mathrm{mmHg}$ and/or a diastolic blood pressure $(\mathrm{DBP}) \geq 90 \mathrm{mmHg}$ and/or receiving antihypertensive treatment was defined as having hypertension [22]. To reduce the bias derived from differences in methodology between studies, cohorts-specific Z-score $(\mathrm{Z}=[\mathrm{X}-\mu] / \sigma)$ was calculated for fasting insulin concentrations. Insulin resistance was estimated by the homeostasis model assessment according to formula of HOMA-IR = (fasting insulin* FPG)/22.5 [23]. The smoking status was classified as current smoker, ex-smoker or non-smoker.

Individuals with a prior history of diabetes or newly diagnosed diabetes (FPG $\geq 7.0 \mathrm{mmol} / \mathrm{l}$ and/or $2 \mathrm{hPG} \geq$ $11.1 \mathrm{mmol} / \mathrm{l}$ ), or pre-diabetes (FPG 6.1-6.9 mmol/l and/ or $2 \mathrm{hPG} 7.8-11.0 \mathrm{mmol} / \mathrm{l}$ ) at baseline were excluded from the current data analysis. The data analysis was restricted to the normoglycemic individuals defined by a FPG $<6.1 \mathrm{mmol} / \mathrm{l}$ and a $2 \mathrm{hPG}<7.8 \mathrm{mmol} / \mathrm{l}$ according to the World Health Organization and International
Diabetes Federation 2006 criteria [24]. The normoglycemic individuals were further classified into Group I if the $2 \mathrm{hPG}$ after a $75 \mathrm{~g}$ oral glucose load was equal to or less than the FPG (2hPG $\leq \mathrm{FPG})$, or group II if the $2 \mathrm{hPG}$ was greater than the FPG (2hPG $>$ FPG).

\section{Definition of CHD and IS events}

First-ever CHD and stroke events occurred before the 31 December 2008 were ascertained through computerized record linkage of the unique national identification numbers of the survey participants to the national Causes of Death Registry and the national Hospital Discharge Registry in both Finnish [25,26] and Swedish [27] studies. Individuals with a history of CHD, myocardial infarction, or stroke diagnosed before the baseline examination were excluded from the current data analysis. Incident CHD events were defined as fatal CHD or nonfatal myocardial infarction; IS events were defined as fatal or non-fatal IS. The International Classification of Diseases (ICD), 9th Revision (10th Revision), were used for the classification of either fatal or non-fatal events: ICD codes 410 to 414 (I20 to I25) for fatal CHD; 410 to 411 (I21 to I22, I24) for non-fatal acute myocardial infarction; 433, 434, 436 (I63 to I64) for fatal and non-fatal IS. A composite CVD event consists of first events of both CHD and IS.

\section{Statistical analysis}

A general linear model was used to estimate the mean of a continuous variable adjusting for age and cohort. The Chi-square test was performed to assess the difference in proportions between groups. Interaction between sex and glucose groups was examined. The Schoenfeld-test was employed to assess the proportional hazards assumption, and the results showed the proportionality assumption was not violated. Cox proportional hazards analysis was employed to estimate hazard ratios (HRs) for CHD, IS incidence and composite CVD events in the Group II as compared with the Group I. In the multivariate Cox model, we adjusted for age, cohort, BMI, FPG, total serum cholesterol, smoking status and hypertension status. The difference between 2hPG and FPG as a continuous variable (2hPG-FPG) was also fitted in a separate multivariate model adjusting for the baseline FPG to examine whether the relationship was linear. In addition, to check whether the "return of the 2hPG to the FPG level" was determined by the FPG levels, the comparison of Group II versus Group I was further assessed by dividing the FPG into two strata of FPG $\leq 5.6 \mathrm{mmol} / \mathrm{l}$ and FPG 5.6-6.1 mmol/l. The statistical analyses were performed using SPSS version 18.0 software (SPSS Inc. Chicago, USA) and STATA version 11.0 software (Stata Corp., TX, USA). A p-value less than 0.05 (two sided tests) was considered statistically significant. 


\section{Results}

Baseline characteristics of the participants are presented in Table 1. During a median follow-up of 16.4 years, a total of 466 (115) CHD, 235 (106) IS and 638 (213) composite CVD events in men (women) were recorded. The incidence of IS, composite CVD events were higher in the Group II than in the Group I in men $(\mathrm{p}<0.05)$, but not in women (Table 2). Both incidences of CHD (7.2 per 1000 person-years versus 1.8 per 1000 person-years) and IS (3.7 per 1000 person-years versus 1.6 per 1000 person-years) were higher in men than in women ( $p<0.05$ for all comparisons). In addition, mean values of various CVD risk factors such as age, BMI, 2hPG, blood pressure, fasting insulin and HOMA-IR were significantly greater in individuals in the Group II than in those in the Group I in both sexes ( $p<0.05$ for all comparisons), except for BMI and systolic blood pressure in women.

Since the interaction between the two glucose groups and sex was statistically significant $(\mathrm{p}<0.001)$, data analyses were made separately for men and women. Multivariate-adjusted HRs for IS and composite CVD events were significantly higher in Group II than in Group I in men, but not in women (Table 3). The survival profile was better in group I than in group II for composite CVD events in both sexes (Figure 1). Replacing the hypertension status (yes versus no) with continuous systolic blood pressure in the Cox model did not change the results substantially (data not shown). HRs corresponding to a one unit increase in the difference between 2hPG and FPG concentrations (2hPG-FPG) were significantly increased for the CHD events in women and composite CVD events in all individuals (Table 3).
Stratified data analysis was also performed by FPG of $\leq 5.6 \mathrm{mmol} / \mathrm{l}$ and $5.6-6.1 \mathrm{mmol} / \mathrm{l}$, and by age of $<60$ years and $\geq 60$ years for both men and women combined. Multivariate-adjusted HRs (95\% CIs) for the composite CVD events for Group II as compared with Group I were 1.09 (0.91-1.30) and 1.41 (1.06-1.86) in the lower and the higher FPG categories; and 1.16 (0.96-1.40) and 1.27 (0.99-1.64), respectively, in the younger and older age groups. In addition, the same data analysis was also made in a subgroup of individuals who had fasting insulin measurements $(\mathrm{n}=4082)$, producing an HR $(95 \% \mathrm{CI})$ of $1.10(0.90-1.34)$ in a model without fasting insulin, to $1.09(0.89-1.33)$ when the model fitting with fasting insulin, and to $1.10(0.90-1.34)$ when replacing fasting insulin with HOMA-IR. Neither the fasting insulin levels nor the HOMA-IR changed the results substantially. The HR $(95 \% \mathrm{CI})$ for the composite CVD events was 1.07 (0.89-1.30) and 1.08 (0.89-1.30), respectively in models without and with physical activity and education in a subgroup of participants $(\mathrm{n}=5331)$.

\section{Discussion}

In these prospective cohort studies, $11.0 \%$ of the participants who had normoglycemia at baseline developed first CHD or IS events during a median follow-up of 16.4 years. The risk to develop the CHD or IS was increased in people whose 2hPG was higher than whose FPG.

Two-hour plasma glucose concentration is a better predictor than FPG for the incidence of CHD $[8,9]$ and IS [10] among general populations with hyperglycemia. Moreover, post-challenge glucose concentrations contribute to a greater risk on the patients with CHD [28] or IS [29-31] than slightly elevated FPG. In contrast, FPG was better predictor than 2hPG for total mortality

Table 1 Baseline characteristics of study cohorts and number of first events of CHD and IS

\begin{tabular}{|c|c|c|c|c|c|c|c|}
\hline \multirow[t]{2}{*}{ Countries and studies } & \multirow{2}{*}{$\begin{array}{c}\text { No. } \\
\text { (men/women) }\end{array}$} & \multirow{2}{*}{$\begin{array}{l}\text { Age years } \\
\text { Mean (range) }\end{array}$} & \multirow{2}{*}{$\begin{array}{c}\mathrm{FPG}^{*} \\
(\mathrm{mmol} / \mathrm{l})\end{array}$} & \multirow{2}{*}{$\begin{array}{l}2 \mathrm{hPG}^{*} \\
(\mathrm{mmol} / \mathrm{l})\end{array}$} & \multicolumn{2}{|c|}{ No. of events (men/women) } & \multirow{2}{*}{$\begin{array}{c}\text { Maximum (Median) } \\
\text { follow-up years }\end{array}$} \\
\hline & & & & & CHD & IS & \\
\hline \multicolumn{8}{|l|}{ Finland } \\
\hline East-West Study & $125 /-$ & $76(70-90)$ & $5.2(0.04)$ & $5.4(0.10)$ & $27 /-$ & 24/- & $16.8(10.4)$ \\
\hline FINRISK 1987 & $859 / 1006$ & $53(44-64)$ & $5.1(0.01)$ & $5.5(0.03)$ & $142 / 59$ & $57 / 46$ & $21.0(20.8)$ \\
\hline FINRISK 1992 & $496 / 747$ & $53(44-64)$ & $5.2(0.01)$ & $5.5(0.03)$ & $32 / 18$ & $8 / 11$ & $16.0(15.9)$ \\
\hline Helsinki Policemen Study & $578 /-$ & $45(31-69)$ & $5.7(0.02)$ & $5.3(0.05)$ & $141 /-$ & $77 /-$ & $36.8(34.5)$ \\
\hline Oulu Study & $93 / 172$ & $55(55-55)$ & $5.4(0.03)$ & $6.1(0.07)$ & $4 / 4$ & $5 / 5$ & $17.3(16.8)$ \\
\hline Vantaa Study & $120 / 168$ & $65(64-66)$ & $5.2(0.03)$ & $6.2(0.07)$ & $16 / 15$ & $14 / 9$ & $17.9(17.3)$ \\
\hline \multicolumn{8}{|l|}{ Sweden } \\
\hline Malmö Prevention Project & $-/ 821$ & $54(48-57)$ & $5.5(0.02)$ & $6.7(0.04)$ & $-/ 2$ & $-/ 16$ & $20.0(14.6)$ \\
\hline MONICA & $923 / 1002$ & $45(25-74)$ & $5.1(0.01)$ & $5.3(0.03)$ & $50 / 17$ & $12 / 19$ & $20.6(16.4)$ \\
\hline ULSAM & $549 /-$ & $71(70-73)$ & $5.1(0.02)$ & $5.5(0.06)$ & $54 /-$ & $38 /-$ & $12.4(10.2)$ \\
\hline Total & $3743 / 3916$ & $53(25-90)$ & $5.2(0.01)$ & $5.6(0.01)$ & $466 / 115$ & 235/106 & $36.8(16.4)$ \\
\hline
\end{tabular}

${ }^{*}$ Age-adjusted means (standard error). FPG, fasting plasma glucose; 2hPG, two-hour plasma glucose; CHD, coronary heart disease; IS, ischemic stroke; MONICA, Monitoring of trends and determinants in cardiovascular disease; ULSAM, the Uppsala Longitudinal Study of Adult Men study. 
Table 2 Characteristics of participants and incidence of CHD and IS according to FPG and 2hPG categories

\begin{tabular}{|c|c|c|c|c|}
\hline & \multicolumn{2}{|c|}{ Men } & \multicolumn{2}{|c|}{ Women } \\
\hline & Group I & Group II & Group I & Group II \\
\hline & $\overline{2 h P G \leq F P G}$ & $\overline{2 \mathrm{hPG}>\mathrm{FPG}}$ & $\overline{2 h P G \leq F P G}$ & $2 \mathrm{hPG}>\mathrm{FPG}$ \\
\hline no. (\%) & $1818(48.6)$ & $1925(51.4)$ & $1110(28.3)$ & $2806(71.7)$ \\
\hline Age (years) & $50(0.28)^{*}$ & $57(0.27)$ & $49(0.25)^{*}$ & $53(0.16)$ \\
\hline Body mass index $\left(\mathrm{kg} / \mathrm{m}^{2}\right)$ & $25.9(0.08)^{*}$ & $26.3(0.07)$ & $25.6(0.13)$ & $25.9(0.08)$ \\
\hline$\overline{\mathrm{FPG}}(\mathrm{mmol} / \mathrm{l})$ & $5.33(0.01)^{*}$ & $5.18(0.01)$ & $5.23(0.01)^{*}$ & $5.18(0.01)$ \\
\hline $2 \mathrm{hPG}(\mathrm{mmol} / \mathrm{l})$ & $4.42(0.02)^{*}$ & $6.23(0.02)$ & $4.55(0.02)^{*}$ & $6.37(0.01)$ \\
\hline Fasting insulin ( $(\mathrm{mol} / \mathrm{l})$ & $-0.07(0.03)^{*+}$ & $0.09(0.03)$ & $-0.13(0.04)^{*}$ & $0.04(0.03)$ \\
\hline HOMA-IR & $-0.04(0.03)^{*}+$ & $0.10(0.03)$ & $-0.13(0.04)^{*}$ & $0.01(0.03)$ \\
\hline Total serum cholesterol (mmol/l) & $6.11(0.03)$ & $6.06(0.03)$ & $6.07(0.03)$ & $6.08(0.02)$ \\
\hline \multicolumn{5}{|l|}{ Blood pressure $(\mathrm{mmHg})$} \\
\hline Systolic & $138(0.42)^{*}$ & $141(0.41)$ & $133(0.59)$ & $135(0.37)$ \\
\hline Diastolic & $84(0.25)^{*}$ & $86(0.25)$ & $82(0.32)^{*}$ & $83(0.20)$ \\
\hline Current smoking (\%) & $32.9^{*}$ & 23.3 & $24.8^{*}$ & 18.9 \\
\hline Hypertension (\%) & $48.7^{*}$ & 64.2 & $45.0^{*}$ & 51.7 \\
\hline \multicolumn{5}{|l|}{ Incidence per1000 person-years (no.) } \\
\hline $\mathrm{CHD}$ & $6.7(225)$ & $7.9(241)$ & $1.3(24)$ & $1.9(91)$ \\
\hline IS & $2.8(96)^{*}$ & $4.5(139)$ & $1.4(25)$ & $1.7(81)$ \\
\hline $\mathrm{CHD}+\mathrm{IS}$ & $8.7(293)^{*}$ & $11.3(345)$ & $2.6(48)$ & $3.5(165)$ \\
\hline
\end{tabular}

Data are age- and cohort- adjusted means (standard error) or as noted. ${ }^{*} \mathrm{p}<0.05$ for difference between the two glucose groups in men or in women; ${ }^{\dagger} \mathrm{Z}$-score for 2443 men and 1639 women who had fasting insulin measurements. CHD, coronary heart disease; FPG, fasting plasma glucose; 2hPG, 2-hour plasma glucose; HOMA-IR, homeostasis model assessment of insulin resistance; IS, ischemic stroke.

and CVD mortality in the CHD patients in another study [32]. A number of studies have shown that IFG and IGT reflect different pathophysiological mechanisms of abnormal glucose homeostasis [33,34]. Fasting hyperglycemia is associated with reduced hepatic insulin resistance and decreased first-phase insulin secretion, while elevated post-challenge glucose concentration is associated with peripheral insulin resistance and impairment of both early- and late-phase insulin response $[35,36]$.
Among individuals with normal glucose range, people whose $2 \mathrm{hPG}$ did not return to their FPG levels during a 2-h OGTT had a significantly higher risk for future type 2 diabetes [16], worse cardiovascular risk profile [37] and higher CVD mortality [17] compared with those whose 2hPG were equal to or lower than their FPG levels. This was further confirmed in our current study with incident CVD events. The normoglycemic status is a balance between glucose production and disposal mediated through a synergistic effect of skeletal muscle,

Table 3 Hazard ratios and $95 \%$ confidence intervals for incidence of coronary heart disease and ischemic stroke

\begin{tabular}{|c|c|c|c|c|c|c|}
\hline & \multicolumn{2}{|c|}{ CHD } & \multicolumn{2}{|c|}{ IS } & \multicolumn{2}{|c|}{ CHD + IS } \\
\hline & HR & $95 \% \mathrm{Cl}$ & HR & $95 \% \mathrm{Cl}$ & HR & $95 \% \mathrm{Cl}$ \\
\hline \multicolumn{7}{|l|}{ Men $(n=3743)$} \\
\hline Group II versus Group I & 1.13 & $0.93-1.37$ & 1.40 & $1.06-1.85$ & 1.20 & $1.01-1.42$ \\
\hline 2hPG-FPG (continuous) & 1.03 & $0.95-1.12$ & 1.11 & $0.99-1.25$ & 1.07 & $0.99-1.14$ \\
\hline \multicolumn{7}{|l|}{ Women $(n=3916)$} \\
\hline Group II versus Group I & 1.33 & $0.83-2.12$ & 0.94 & $0.59-1.50$ & 1.10 & $0.79-1.54$ \\
\hline 2hPG-FPG (continuous) & 1.24 & $1.03-1.50$ & 1.01 & $0.83-1.23$ & 1.13 & $0.99-1.30$ \\
\hline \multicolumn{7}{|l|}{ Total $(n=7659)$} \\
\hline Group II versus Group I & 1.15 & $0.97-1.38$ & 1.27 & $1.00-1.62$ & 1.18 & $1.02-1.37$ \\
\hline 2hPG-FPG (continuous) & 1.06 & $0.98-1.14$ & 1.09 & $0.98-1.20$ & 1.08 & $1.01-1.15$ \\
\hline
\end{tabular}

Adjusting for age, cohort, body mass index, FPG, total serum cholesterol, smoking status and hypertension status, and sex when men and women combined. CHD, coronary heart disease; $95 \% \mathrm{Cl}, 95 \%$ confidence interval; FPG, fasting plasma glucose; Group I, $2 \mathrm{hPG} \leq \mathrm{FPG}$; Group II, 2hPG > FPG; 2hPG, 2-hour plasma glucose; 2hPG-FPG, the difference between 2hPG and FPG; HR, hazard ratio; IS, ischemic stroke. 


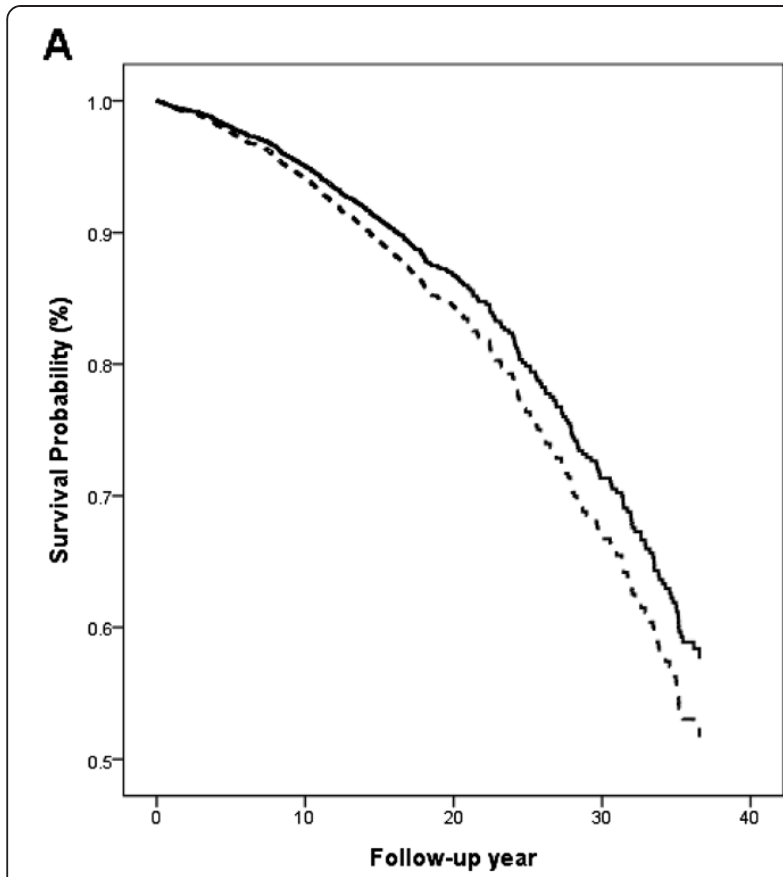

B

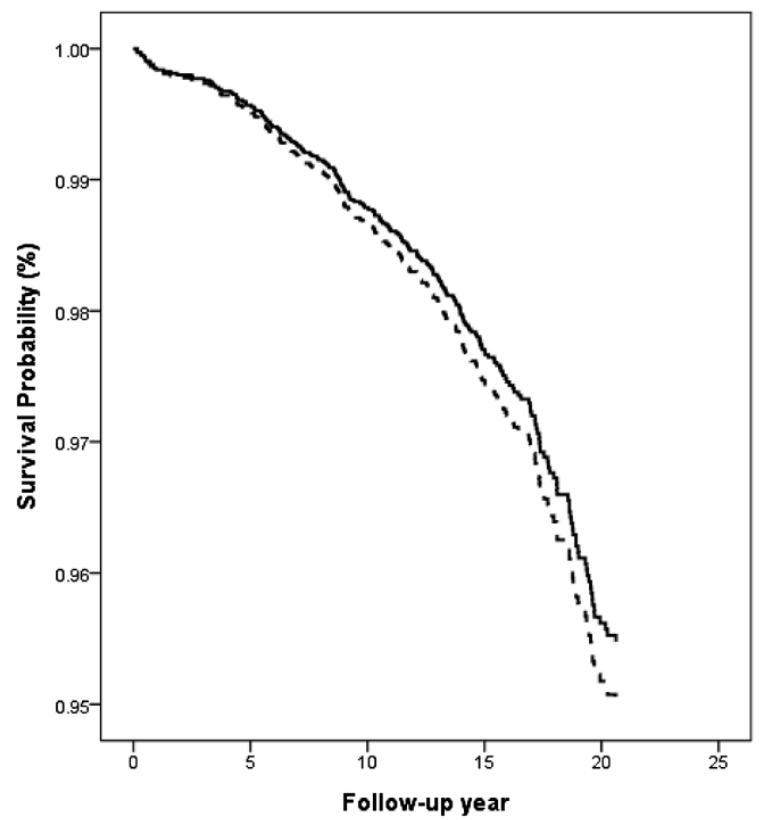

Figure 1 Survival curves for incidence of composite CVD events derived from Cox regression analysis for Group I (solid line) and Group II (dashed line) in men (A) and in women (B). The

analyses were adjusted for age, cohort, fasting plasma glucose, body mass index, total cholesterol, smoking and hypertension status.

pancreas beta cells and liver [38]. Elevated fasting insulin levels have been shown to contribute to the progress to diabetes and CVD among individuals with normoglycemia $[16,37]$. Our study showed that normoglycemic individuals whose $2 \mathrm{hPG}$ did not return to FPG levels had elevated fasting insulin levels and HOMA-IR compared with those who did. Beta-cell dysfunction and insulin resistance have been suggested to be present already in individuals with normal glucose range [11,39]. Both insulin resistance and endothelial dysfunction have been considered as the underlying mechanism contributing to the development of atherosclerosis [40-44]. Other proposed factors include elevated plasma free fatty acids concentrations, which appears to be an early trigger for multiple pathways leading to atherogenesis in nondiabetic healthy subjects [45], and elevated fetuin-A levels which are associated with an increased risk of myocardial infarction and IS in the general population [46]. While these have been reported to be associated with development of CVD in non-diabetic individuals, to what extent these factors contribute to the increased risk of CVD in people with high normal 2hPG is not known, and needs to be further investigated.

The strengths of our study include a relatively long duration of follow-up, a large sample size and a standard 2-h OGTT to define normoglycemia. In this collaborative analysis, all studies were population-based with a random sampling method except for the Helsinki Policemen Study. To take into account the discrepancies between cohorts, the cohort was adjusted as a covariate in the data analysis. The Finnish [25,26] and Swedish [27] Causes of Death Register and Hospital Discharge Register, the source of the data on CHD and IS events in this study, have high coverage and diagnostic accuracy. Our study has also certain limitations. The statistical power of the analysis was relatively lower in women due to small number of incident events. Other known cardiovascular risk factors, such as waist circumference, HbA1c levels and dietary factors were not available for all cohorts included in the current data analysis. Lipidlowering treatment, types of antihypertensive treatment and hormone replacement therapy for the postmenopausal women were not included in the current database. Furthermore, we did not have any measurements of markers of inflammation and endothelial dysfunction, both of which have been shown to relate more strongly to post-load than to fasting plasma glucose concentrations, and might represent unmeasured confounders which underlie the observed relationships $[47,48]$. To what extent these missing variables will affect the results is not known and need to be further investigated.

\section{Conclusion}

In the normoglycemic range defined by both $2 \mathrm{hPG}$ and FPG criteria, 2hPG after a 75 g OGTT unable to return to the FPG level was associated with worse CVD profile, elevated fasting insulin levels and increased CVD events. The underlying mechanism and clinical implications need to be further investigated. 


\section{Abbreviations}

BMI: Body mass index; CHD: Coronary heart disease; 95\% Cl: 95\% confidence interval; CVD: Cardiovascular disease; DECODE: Diabetes Epidemiology: Collaborative analysis Of Diagnostic criteria in Europe; FPG: Fasting plasma glucose; 2hPG: 2-hour plasma glucose; HR: Hazard ratio; IS: Ischemic stroke; OGTT: Oral glucose tolerance test.

\section{Competing interests}

The authors declare that they have no competing interests.

\section{Acknowledgements}

This work was supported by the Academy of Finland [129197]. We gratefully acknowledge the contribution of investigators from the collaborative study of the DECODE Study (Diabetes Epidemiology: Collaborative analysis Of Diagnostic Criteria in Europe):

Finland East-West Study: A Nissinen 1, J Pekkanen ${ }^{1}$, J Tuomilehto ${ }^{1,2,3,4} .1$ Diabetes Prevention Unit, Department of Chronic Disease Prevention, National Institute for Health and Welfare, Helsinki; 2. Department of Public Health, Hjelt Institute, University of Helsinki, Helsinki; 3. South Ostrobothnia Central Hospital, Seinäjoki; 4. Red RECAVA Grupo RD06/0014/0015, Hospital Universitario La Paz, Madrid, Spain.

Helsinki Policemen Study: M Pyörälä, K Pyörälä. Institute of Clinical Medicine, Faculty of Health Sciences, University of Eastern Finland, Kuopio. National FINRISK 1987 and 1992 Cohorts: J Tuomilehto 1,2,3,4, P Jousilahti ${ }^{2}$, J Lindström². 1. Department of Public Health, Hjelt Institute, University of Helsinki, Helsinki; 2. Department of Chronic Disease Prevention, National Institute for Health and Welfare, Helsinki; 3. South Ostrobothnia Central Hospital, Seinäjoki; 4. Red RECAVA Grupo RD06/0014/0015, Hospital Universitario La Paz, Madrid, Spain.

Oulu Study: S Keinänen-Kiukaanniemi ${ }^{1,2,3}$, U Rajala ${ }^{1}, M_{\text {Laakso }}{ }^{1,3}, 1$. The Institute of Health Sciences, University of Oulu, Oulu; 2. Oulu Health Centre, Oulu; 3. Unit of General Practice, Oulu University Hospital, Oulu. Vantaa Study: R Tilvis ${ }^{1}$, J Tuomilehto $2,3,4,5$. 1. Division of Geriatrics, Department of Medicine, University of Helsinki, Helsinki; 2. Department of Public Health, Hjelt Institute, University of Helsinki, Helsinki; 3. Diabetes Prevention Unit, Department of Chronic Disease Prevention, National Institute for Health and Welfare, Helsinki; 4. South Ostrobothnia Central Hospital, Seinäjoki; 5. Red RECAVA Grupo RD06/0014/0015, Hospital Universitario La Paz, Madrid, Spain.

Sweden Malmö Preventive Project: P M Nilsson, G Berglund. Department of Clinical Sciences, Lund University, University Hospital, Malmö. Northern Sweden MONICA: S Söderberg ${ }^{1,2}$, M Eliasson? 1.1 . Department of Public Health and Clinical Medicine, University of Umeå, Umeå; 2. Baker IDI Heart and Diabetes Institute, Melbourne, Australia.

The Uppsala Longitudinal Study of Adult Men (ULSAM): B Zethelius. Department of Public Health/Geriatrics, Uppsala University Hospital, Uppsala.

\section{Author details}

${ }^{1}$ Department of Public Health, Hjelt Institute, University of Helsinki, Helsinki, Finland. ${ }^{2}$ Department of Chronic Disease Prevention, National Institute for Health and Welfare, Helsinki, Finland. ${ }^{3}$ Qingdao Endocrine \& Diabetes Hospital, Qingdao, China. ${ }^{4}$ Weifang Medical University, Weifang, China. ${ }^{5}$ Department of Epidemiology and Biostatistics EMGO, Institute for Health and Care Research VU University Medical Center, Amsterdam, the Netherlands. ${ }^{6}$ Turkish Society of Cardiology, Istanbul, Turkey. ${ }^{7}$ Department of Cardiology, Cerrahpaşa Medical Faculty, Istanbul University, Istanbul, Turkey. ${ }^{8}$ Department of Internal Medicine and Cardiovascular Research Institute Maastricht, Maastricht University Medical Centre, Maastricht, the Netherlands. ${ }^{9}$ University College London, WC1E 6BT, London, UK. ${ }^{10}$ South Ostrobothnia Central Hospital, Seinäjoki, Finland. ${ }^{11}$ Red RECAVA Grupo RD06/0014/0015, Hospital Universitario La Paz, Madrid, Spain. ${ }^{12}$ Institute of Clinical Medicine, Faculty of Health Sciences, University of Eastern Finland, Kuopio, Finland.

\section{Authors' contributions}

FN carried out the data analysis and drafted the manuscript. QQ participated in the concept design, funding and coordination of the study and in drafting the manuscript. AO, CDAS, JMD, JSY, JT, KP, LZ and TL contributed to data collection, discussion and approved the final version of the manuscript.
Received: 14 March 2012 Accepted: 25 June 2012

Published: 25 June 2012

\section{References}

1. Rodriguez BL, Lau NB, Cecil M, Abbott RD, Sharp DS, Yano K, Curb JD: Glucose intolerance and 23-year risk of coronary heart disease and total mortality: the Honolulu Heart Program. Diabetes Care 1999, 22:1262-1265.

2. Doi $Y$, Ninomiya $T$, Hata J, Fukuhara M, Yonemoto $K$, I wase M, lida M, Kiyohara Y: Impact of glucose tolerance status on development of ischemic stroke and coronary heart disease in a general Japanese population: the Hisayama Study. Stroke 2010, 41:203-209.

3. Fujishima M, Kiyohara Y, Kato I, Ohmura T, Iwamoto H, Nakayama K, Ohmori S, Yoshitake T: Diabetes and cardiovascular disease in a prospective population survey in Japan: the Hisayama Study. Diabetes 1996, 45(Suppl 3):14S-16S.

4. Hyvarinen M, Qiao Q, Tuomilehto J, Laatikainen T, Heine RJ, Stehouwer CD, Alberti KG, Pyorala K, Zethelius B, Stegmayr B, DECODE Study Group: Hyperglycemia and stroke mortality: comparison between fasting and 2-h glucose criteria. Diabetes Care 2009, 32:348-354.

5. de Vegt F, Dekker JM, Ruhe HG, Stehouwer CD, Nijpels G, Bouter LM, Heine $\mathrm{RJ}$ : Hyperglycaemia is associated with all-cause and cardiovascular mortality in the Hoorn population: the Hoorn Study. Diabetologia 1999, 42:926-931.

6. Levitan EB, Song Y, Ford ES, Liu S: Is nondiabetic hyperglycemia a risk factor for cardiovascular disease? a meta-analysis of prospective studies. Arch Intern Med 2004, 164:2147-2155.

7. Barr EL, Boyko EJ, Zimmet PZ, Wolfe R, Tonkin AM, Shaw JE: Continuous relationships between non-diabetic hyperglycaemia and both cardiovascular disease and all-cause mortality: the Australian Diabetes, Obesity, and Lifestyle (AusDiab) study. Diabetologia 2009, 52:415-424.

8. Smith NL, Barzilay Jl, Shaffer D, Savage PJ, Heckbert SR, Kuller LH, Kronmal RA, Resnick HE, Psaty BM: Fasting and 2-hour postchallenge serum glucose measures and risk of incident cardiovascular events in the elderly: the cardiovascular health study. Arch Intern Med 2002, 162:209-216.

9. Qiao Q, Pyorala K, Pyorala M, Nissinen A, Lindstrom J, Tilvis R, Tuomilehto J: Two-hour glucose is a better risk predictor for incident coronary heart disease and cardiovascular mortality than fasting glucose. Eur Heart $J$ 2002, 23:1267-1275

10. Hyvarinen M, Tuomilehto J, Mahonen M, Stehouwer CD, Pyorala K, Zethelius B, Qiao Q, DECODE Study Group: Hyperglycemia and incidence of ischemic and hemorrhagic stroke-comparison between fasting and 2-hour glucose criteria. Stroke 2009, 40:1633-1637.

11. Piche ME, Lemieux S, Perusse L, Weisnagel SJ: High normal 2-hour plasma glucose is associated with insulin sensitivity and secretion that may predispose to type 2 diabetes. Diabetologia 2005, 48:732-740.

12. Ferrannini E, Gastaldelli A, Miyazaki Y, Matsuda M, Mari A, DeFronzo RA: beta-Cell function in subjects spanning the range from normal glucose tolerance to overt diabetes: a new analysis. J Clin Endocrinol Metab 2005, 90:493-500.

13. Weyer C, Bogardus C, Mott DM, Pratley RE: The natural history of insulin secretory dysfunction and insulin resistance in the pathogenesis of type 2 diabetes mellitus. J Clin Invest 1999, 104:787-794.

14. Tirosh A, Shai I, Tekes-Manova D, Israeli E, Pereg D, Shochat T, Kochba I, Rudich A, Israeli Diabetes Research Group: Normal fasting plasma glucose levels and type 2 diabetes in young men. N Engl J Med 2005, 353:1454-1462.

15. Tanne D, Koren-Morag N, Goldbourt U: Fasting plasma glucose and risk of incident ischemic stroke or transient ischemic attacks: a prospective cohort study. Stroke 2004, 35:2351-2355.

16. Abdul-Ghani MA, Williams K, DeFronzo R, Stern M: Risk of progression to type 2 diabetes based on relationship between postload plasma glucose and fasting plasma glucose. Diabetes Care 2006, 29:1613-1618.

17. Ning F, Tuomilehto J, Pyorala K, Onat A, Soderberg S, Qiao Q, DECODE Study Group: Cardiovascular disease mortality in Europeans in relation to fasting and 2-h plasma glucose levels within a normoglycemic range. Diabetes Care 2010, 33:2211-2216.

18. DECODE study group: Glucose tolerance and mortality: comparison of WHO and American Diabetes Association diagnostic criteria. DECODE Study Group on behalf of the European Diabetes Epidemiology Study Group. Lancet 1999, 354:617-621 
19. DECODE study group: Glucose tolerance and cardiovascular mortality: comparison of fasting and 2-hour diagnostic criteria. DECODE Study Group on behalf of the European Diabetes Epidemiology Study Group. Arch Intern Med 2001, 161:397-405.

20. DECODE study group: Will new diagnostic criteria for diabetes mellitus change phenotype of patients with diabetes? Reanalysis of European epidemiological data. DECODE Study Group on behalf of the European Diabetes Epidemiology Study Group. BMJ 1998, 317:371-375.

21. DECODE study group: Is fasting glucose sufficient to define diabetes? Epidemiological data from 20 European studies. European Diabetes Epidemiology Group. Diabetes Epidemiology: Collaborative analysis of Diagnostic Criteria in Europe. Diabetologia 1999, 42:647-654.

22. World Health Organization: World Health Organization-International Society of Hypertension Guidelines for the Management of Hypertension. Guidelines Subcommittee. J Hypertens 1999, 1999(17):151-183.

23. Matthews DR, Hosker JP, Rudenski AS, Naylor BA, Treacher DF, Turner RC: Homeostasis model assessment: insulin resistance and beta-cell function from fasting plasma glucose and insulin concentrations in man. Diabetologia 1985, 28:412-419.

24. World Health Organization and International Diabetes Federation Consultation: Definition and diagnosis of diabetes mellitus and intermediate hyperglycaemia: report of a WHO/IDF consultation. Geneva: World Health Organization; 2006.

25. Mahonen M, Salomaa V, Keskimaki I, Moltchanov V, Torppa J, Molarius A, Tuomilehto J, Sarti C, FINMONICA Stroke Register Study group: The feasibility of combining data from routine Hospital Discharge and Causes-of-Death Registers for epidemiological studies on stroke. Eur J Epidemiol 2000, 16:815-817.

26. Pajunen $\mathrm{P}$, Koukkunen $\mathrm{H}$, Ketonen $\mathrm{M}$, Jerkkola $\mathrm{T}$, Immonen-Raiha $\mathrm{P}$, KarjaKoskenkari P, Mahonen M, Niemela M, Kuulasmaa K, Palomaki P, Mustonen J, Lehtonen A, Arstila M, Vuorenmaa T, Lehto S, Miettinen H, Torppa J, Tuomilehto J, Kesaniemi YA, Pyorala K, Salomaa V: The validity of the Finnish Hospital Discharge Register and Causes of Death Register data on coronary heart disease. Eur J Cardiovasc Prev Rehabil 2005, 12:132-137.

27. Stegmayr B, Asplund K: Measuring stroke in the population: quality of routine statistics in comparison with a population-based stroke registry. Neuroepidemiology 1992, 11:204-213.

28. Schinner S, Futh R, Kempf K, Martin S, Willenberg HS, Schott M, Dinh W, Scherbaum WA, Lankisch M: A progressive increase in cardiovascular risk assessed by coronary angiography in non-diabetic patients at subdiabetic glucose levels. Cardiovasc Diabetol 2011, 10:56.

29. Ivey FM, Ryan AS, Hafer-Macko CE, Garrity BM, Sorkin JD, Goldberg AP, Macko RF: High prevalence of abnormal glucose metabolism and poor sensitivity of fasting plasma glucose in the chronic phase of stroke. Cerebrovasc Dis 2006, 22:368-371.

30. Jia Q, Zheng H, Liu L, Zhao X, Wang C, Jing J, Liang D, Wang Y, Zhou Y, Dong $K$, Yang Z, Wang $Y$ : Persistence and predictors of abnormal glucose metabolisms in patients after acute stroke. Neurol Res 2010, 32:359-365.

31. Jia Q, Zheng H, Zhao X, Wang C, Liu G, Wang Y, Liu L, Li H, Zhong L, Wang $Y$, Investigators for the Survey on Abnormal Glucose Regulation in Patients With Acute Stroke Across China (ACROSS-China): Abnormal glucose regulation in patients with acute stroke across China: prevalence and baseline patient characteristics. Stroke 2012, 43:650-657.

32. Gayda M, Bourassa MG, Tardif JC, Fortier A, Juneau M, Nigam A: Effects of fasting and/or postprandial glucose on heart rate recovery in patients with coronary heart disease. Diabetes Metab 2012, 38:20-26.

33. Laakso M, Zilinskaite J, Hansen T, Boesgaard TW, Vanttinen M, Stancakova A Jansson PA, Pellme F, Holst JJ, Kuulasmaa T, Hribal ML, Sesti G, Stefan N, Fritsche A, Haring H, Pedersen O, Smith U, EUGENE2 Consortium: Insulin sensitivity, insulin release and glucagon-like peptide-1 levels in persons with impaired fasting glucose and/or impaired glucose tolerance in the EUGENE2 study. Diabetologia 2008, 51:502-511.

34. Nathan DM, Davidson MB, DeFronzo RA, Heine RJ, Henry RR, Pratley R, Zinman B: Impaired fasting glucose and impaired glucose tolerance. Diabetes Care 2007, 30:753-759.

35. Festa A, D'Agostino R, Hanley AJG, Karter AJ, Saad MF, Haffner SM: Differences in insulin resistance in nondiabetic subjects with isolated impaired glucose tolerance or isolated impaired fasting glucose. Diabetes 2004, 53:1549-1555.

36. Meyer C, Pimenta W, Woerle HJ, Van Haeften T, Szoke E, Mitrakou A, Gerich J: Different mechanisms for impaired fasting glucose and impaired postprandial glucose tolerance in humans. Diabetes Care 2006, 29:1909-1914.

37. Succurro E, Marini MA, Grembiale A, Lugara M, Andreozzi F, Sciacqua A, Hribal ML, Lauro R, Perticone F, Sesti G: Differences in cardiovascular risk profile based on relationship between post-load plasma glucose and fasting plasma levels. Diabetes Metab Res Rev 2009, 25:351-356.

38. DeFronzo RA: Lilly lecture 1987. The triumvirate: beta-cell, muscle, liver. A collusion responsible for NIDDM. Diabetes 1988, 37:667-687.

39. Kahn SE: The importance of beta-cell failure in the development and progression of type 2 diabetes. J Clin Endocrinol Metab 2001, 86:4047-4058

40. Dignat-George F, Sampol J: Circulating endothelial cells in vascular disorders: new insights into an old concept. Eur J Haematol 2000 65:215-220

41. Bakker W, Eringa EC, Sipkema P, van Hinsbergh W: Endothelial dysfunction and diabetes: roles of hyperglycemia, impaired insulin signaling and obesity. Cell Tissue Res 2009, 335:165-189.

42. Goldfine AB, Beckman JA, Betensky RA, Devlin H, Hurley S, Varo N, Schonbeck U, Patti ME, Creager MA: Family history of diabetes is a major determinant of endothelial function. J Am Coll Cardiol 2006, 47:2456-2461.

43. Boger RH, Bode-Boger SM, Szuba A, Tsao PS, Chan JR, Tangphao O, Blaschke TF, Cooke JP: Asymmetric dimethylarginine (ADMA): a novel risk factor for endothelial dysfunction: its role in hypercholesterolemia. Circulation 1998, 98:1842-1847.

44. Balletshofer BM, Rittig K, Enderle MD, Volk A, Maerker E, Jacob S, Matthaei S, Rett K, Haring HU: Endothelial dysfunction is detectable in young normotensive first-degree relatives of subjects with type 2 diabetes in association with insulin resistance. Circulation 2000, 101:1780-1784.

45. Mathew M, Tay E, Cusi K: Elevated plasma free fatty acids increase cardiovascular risk by inducing plasma biomarkers of endothelial activation, myeloperoxidase and PAI-1 in healthy subjects. CardiovasC Diabetol 2010, 9:9.

46. Weikert C, Stefan N, Schulze MB, Pischon T, Berger K, Joost H, Haring H, Boeing $H$, Fritsche A: Plasma fetuin-A levels and the risk of myocardial infarction and ischemic stroke. Circulation 2008, 118:2555-2562.

47. Yudkin JS, Stehouwer CDA, Emeis JJ, Coppack SW: C-reactive protein in healthy subjects: associations with obesity, insulin resistance, and endothelial dysfunction: a potential role for cytokines originating from adipose tissue? Arterioscler Thromb Vasc Biol 1999, 19:972-978.

48. Yudkin JS: Post-load hyperglycaemia-an inappropriate therapeutic target. Lancet 2002, 359:166-167.

\section{doi:10.1186/1475-2840-11-76}

Cite this article as: Ning et al:: Development of coronary heart disease and ischemic stroke in relation to fasting and 2-hour plasma glucose levels in the normal range. Cardiovascular Diabetology 2012 11:76.

\section{Submit your next manuscript to BioMed Central and take full advantage of:}

- Convenient online submission

- Thorough peer review

- No space constraints or color figure charges

- Immediate publication on acceptance

- Inclusion in PubMed, CAS, Scopus and Google Scholar

- Research which is freely available for redistribution 